\title{
The relationship between carbon dioxide, crop and food production index in Ghana: By estimating the long-run elasticities and variance decomposition
}

\author{
Samuel Asumadu Sarkodie ${ }^{1^{\dagger}}$, Phebe Asantewaa Owusu ${ }^{2}$ \\ ${ }^{1}$ Department of Environmental Science, Faculty of Science and Technology, Macquarie University, NSW 2109, Australia \\ ${ }^{2}$ Sustainable Environment and Energy Systems, Middle East Technical University, Northern Cyprus Campus, Kalkanli, Guzelyurt, TRNC 99738 / Mersin \\ 10, Turkey
}

\begin{abstract}
The study estimated the relationship between carbon dioxide, crop and livestock production index in Ghana: Estimating the long-run elasticities and variance decomposition by employing a time series data spanning from 1960-2013 using both fit regression and ARDL models. There was evidence of a long-run equilibrium relationship between carbon dioxide emissions, crop production index and livestock production index. Evidence from the study shows that a $1 \%$ increase in crop production index will increase carbon dioxide emissions by $0.52 \%$, while a $1 \%$ increase in livestock production index will increase carbon dioxide emissions by $0.81 \%$ in the long-run. There was evidence of a bidirectional causality between a crop production index and carbon dioxide emissions and a unidirectional causality exists from livestock production index to carbon dioxide emissions. Evidence from the variance decomposition shows that $37 \%$ of future fluctuations in carbon dioxide emissions are due to shocks in the crop production index while $18 \%$ of future fluctuations in carbon dioxide emissions are due to shocks in the livestock production index. Efforts towards reducing pre-production, production, transportation, processing and post-harvest losses are essential to reducing food wastage which affects Ghana's carbon footprint.
\end{abstract}

Keywords: Carbon dioxide emissions, Econometrics, Food production, Ghana, Variance decomposition

\section{Introduction}

Carbon dioxide emissions, a global burden, have become a global concern as a result of increasing population, increasing energy demand, increasing economic growth and increasing agriculture production to achieve food security [1-4]. The growth-rate of carbon dioxide has increased from 1979-2014, "averaging about $1.4 \mathrm{ppm}$ per year before 1995 and 2.0 ppm per year thereafter" [5, 6]. This global burden has triggered global actions through the 2030 Agenda known as the Sustainable Development Goals in order to transform the world into achieving Sustainable Development [7]. Access to energy either from electricity or food plays a role in socioeconomic development. This essential benefit of human development led to the formation of the Sustainable Development Goals [8, 9]. Sustainable Development Goals (SDGs) 2 and 13 are motivational factors in the study. SDG 2 focuses on ending hunger, achiev- ing food security, improving nutrition and promoting sustainable agriculture while SDG 13 focuses on taking urgent action towards climate change mitigation and its impacts [7].

The motivation of the study follows the food waste campaign by Save Food Initiative. According to Think.Eat.Save [10], the global carbon footprint excluding land use change, has been estimated at 3.3 Giga tons of carbon dioxide equivalent in 2007. The overall volume of food waste in 2007 cost an estimated US $\$ 750$ billion, which was equivalent to Switzerland's gross domestic product (GDP) in 2011. Moreover, meat production and consumption generates $21 \%$ of total food waste carbon footprint globally. This is because wastage of meat generates a substantial impact on the environment in terms of land, occupation and carbon footprint, especially in a higher income region that waste about $67 \%$ of meat. Cereals account for about one-third of the total carbon footprint of food waste, due to nitrogen fertilizers used in crop production,
This is an Open Access article distributed under the terms of the Creative Commons Attribution Non-Commercial License (http://creativecommons.org/licenses/by-nc/3.0/) which permits unrestricted non-commercial use, distribution, and reproduction in any medium, provided the original work is properly cited.
Received November 3, 2016 Accepted January 5, 2017

${ }^{\dagger}$ Corresponding author

Email: asumadusarkodiesamuel@yahoo.com

Tel: $+61-420876983$

Copyright (C) 2017 Korean Society of Environmental Engineers 
diesel use for ploughing and transporting harvested crops, harvesting and drying cereals all results in carbon dioxide emissions. Exclusively, rice production takes a big share of the aforementioned impacts since rice paddies are the major emitters of methane [10].

Since agriculture (crop and livestock production) takes a huge share of Ghana's GDP, the study estimates the relationship between carbon dioxide, crop and food production index in Ghana: by estimating the long-run elasticities and variance decomposition. In order to meet the goal of the study, the following objectives are followed; to ascertain the relationship between carbon dioxide, crop and livestock production index, to estimate the long-run equilibrium relationship between carbon dioxide, crop and livestock production index and estimate the carbon footprint using the variance decomposition between carbon dioxide, crop and livestock production index.

The remainder of the study comprises of; Section 2: "Literature Review", Section 3: "Methodology", Section 4: "Results and Discussions", Section 5: "Policy Recommendations" and Section 6: "Conclusions".

\section{Literature Review}

There are growing scientific research on carbon dioxide emissions using traditional estimation method or modern econometric techniques. The traditional estimation method tries to estimate the carbon footprint. Carbon footprint estimates the cumulated carbon dioxide emissions produced by an individual, livestock, crops, organization or a country. Hauggaard-Nielsen et al. [11] estimated the carbon footprint of perennial crops using the life cycle analysis. Their study revealed that low-input nitrogen crops have a lower carbon footprint in the life cycle analysis than crops with higher nitrogen input. Persson et al [12] developed a new method for the life cycle analysis of carbon footprint evaluation of agricultural commodities in Brazil.

Using traditional estimation methods like life cycle analysis for carbon footprint analysis is useful in examining how the lifestyle of an individual, livestock, crops, organization or a country affect climate change. Moreover, life cycle analysis of carbon footprint investigations provide guidelines to identify systems, technologies, or processes that the lifestyle of an individual, livestock, crops, organization or a country can be improved towards climate change mitigation. Nevertheless, using life cycle analysis for carbon footprint evaluation has some limitations regarding different metrics leading to different results and different policy recommendations. According to Picasso et al. [13], there is a significant quid pro quo existing between carbon footprint and other pertinent environmental variables. Laurent et al [14] revealed the limitations of carbon footprint as environmental sustainability indicator and further suggested a broader technique for environmental sustainability assessment and management. Apart from quantifying carbon footprint, there is a limitation in estimating the long-run equilibrium and the Granger-causality between carbon dioxide emissions and other relevant econometric variables using life cycle analysis. In this way, using modern econometric approaches is more valuable in the presence of either panel data or time series data.

Many studies have employed econometric techniques to investigate the causal nexus between carbon dioxide, energy pro- duction/consumption, economic growth and environmental pollutants by either testing the validity of the Environmental Kuznets Curve (EKC) hypothesis or not [15-21] nevertheless, using econometric techniques for investigating agricultural commodities are sporadic and limited especially in Ghana. Asumadu-Sarkodie and Owusu [22] examined the Kaya factors (carbon dioxide emissions, energy consumption, population and economic growth) in Ghana using the vector error correction model by employing a data spanning from 1980-2012. There was evidence of bidirectional causality between carbon dioxide emissions and energy consumption, and economic growth and energy consumption. Wang et al. [17] investigated the causal relationship between carbon dioxide emissions, economic growth and energy consumption in China by using a data spanning from 1990-2012. There was evidence of bi-directional causality between energy consumption and economic growth. Asumadu-Sarkodie and Owusu [16] estimated the relationship between carbon dioxide emissions and agriculture in Ghana by comparing vector error correction model and autoregressive distributed lag (ARDL) model using a data spanning from 1961-2012. Both models employed in the study showed evidence of a causal relationship between carbon dioxide emissions and agriculture, however, they argue that the relationship dies over-time.

Our study is in line with Bildirici [23] who estimated biomass consumption and GDP by employing the ARDL bound test. Their study revealed that biomass energy consumption has a positive effect on GDP. In contrast to their study using a panel data, our study uses a time series data on carbon dioxide, crop and livestock production index to estimate the long-run elasticities using the ARDL approach and the variance decomposition based on vector error correction model (VECM).

To the best of our knowledge, it is the first time the scope of the study has been proposed in Ghana. The study will increase the global debate on climate change mitigation through the reduction of the carbon footprint from the perspective of a developing country like Ghana. Significantly, the study contributes to the existing literature by quantifying the rate of Ghana's carbon footprint using the long-run elasticities and Cholesky's variance decomposition technique to highlight and analyze the effect of Ghana's carbon footprint. Moreover, the study proposes some policies that will boost Ghana's national food production and consumption policies, agricultural strategies and planning towards climate change mitigation and sustainable development.

\section{Methodology}

The study estimates the relationship between carbon dioxide, crop and food production index in Ghana: By estimating the long-run elasticities using the ARDL model and variance decomposition.

\subsection{Data}

The study employs a time series data spanning from 1960-2013, obtained from the World Bank database [24]. Data includes; $\mathrm{CO}_{2}$-Carbon dioxide emissions (kt), $\mathrm{CP}$ index-Crop production in$\operatorname{dex}(2004-2006=100)$, LP_index-Livestock production index 

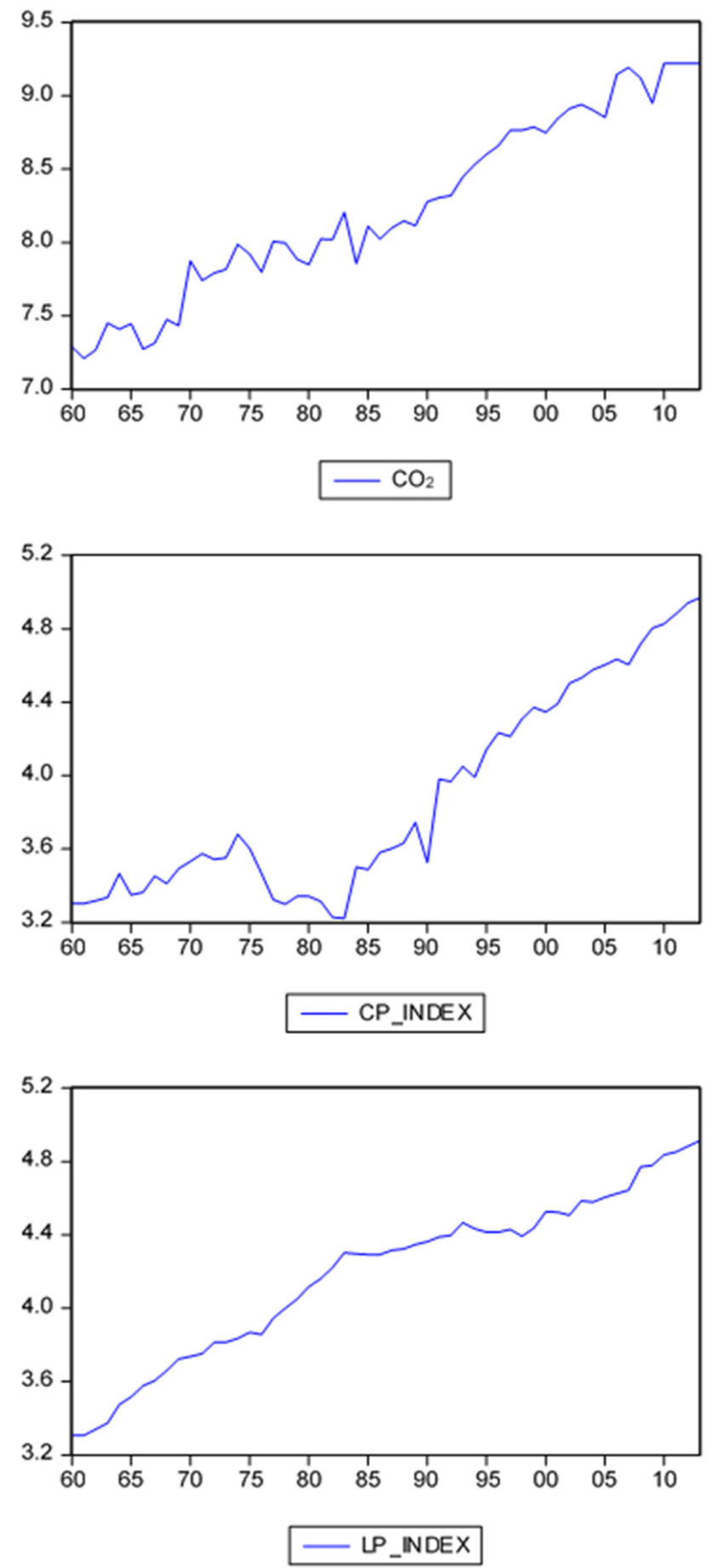

Fig. 1. Trend of variables.

$(2004-2006=100)$. The World Bank [24] defines Crop production index as the "agricultural production for each year relative to the base period 2004-2006, which includes all crops except fodder crops”. In contrast, The World Bank [24] defines Livestock production index as the agricultural production that "includes meat and milk from all sources, dairy product such as cheese, and eggs, honey, raw silk, wool, and hides and skins”. Fig. 1 shows the trend of the time series variables. Evidence from Fig. 1 shows that carbon dioxide emissions, crop and livestock production index show an upward trend across time.

\subsection{Econometric Model}

The long-run elasticities and variance decomposition estimate between carbon dioxide emissions, crop and livestock production index in Ghana can be represented in a linear function expressed as:

$$
C O_{2_{t}}=f\left(C P_{-} \text {index } x_{t}, L P_{-} \text {index } x_{t}\right)
$$

A natural logarithmic transformation was applied to the study variables in order to have a more stable data variance. Let $\operatorname{lnCO}_{2}$, lnCP_index and lnLP_index represent a natural logarithmic transformation of $\mathrm{CO}_{2}, \mathrm{CP}$ index and LP_index. The fit regression model is used to examine the relationship between $\operatorname{lnCO}_{2}, \operatorname{lnCP}$ index and lnLP_index which is expressed as:

$$
\ln C O_{2_{t}}=\beta_{0}+\beta_{1} \ln C P_{-} \text {index } x_{t}+\beta_{2} \ln L P_{-} \text {inde } x_{t}+S
$$

Where $\ln \mathrm{CO}_{2_{t}}$ is the response variable while $\ln C P_{-}$index $x_{t}$ and $\ln L P_{-}$index $_{t}$ are the predictor variables in year $t, S$ is the error and $\beta_{0}, \beta_{1}$ and $\beta_{2}$ are the coefficients that estimates the change in the mean response for each unit change in the predictor value.

In order to the long-run elasticities and variance decomposition of Ghana's carbon footprint, the study employs the ARDL method of cointegration by Pesaran and Shin [25] owing to the relatively small sample size used. ARDL method of cointegration was selected owing to its unbiased estimates and efficiency than the other cointegration methods if applied to small-sample-size [26]. The ARDL model for the study is expressed as:

$$
\begin{aligned}
\triangle \ln C O_{2_{t}}= & \alpha_{0}+\partial_{1} l n C O_{2_{t-1}}+\partial_{2} \ln C P_{-} \text {index }_{t-1}+\partial_{3} \ln L P_{-} \text {index } x_{t-1}+ \\
& \sum_{i=1}^{p} \beta_{1 j} \triangle \ln C O_{2_{t-i}}+\sum_{i=0}^{p} \beta_{2 j} \Delta l n C P_{-} \text {index } x_{t-i}+ \\
& \sum_{i=0}^{p} \beta_{3 j} \Delta l n L P_{-} \text {index } x_{t-i}+\epsilon_{t}
\end{aligned}
$$

Where $\alpha$ is the intercept term, $\beta$ 's are the parameters to be estimated, $p$ is the lag order, $\epsilon_{t}$ is the white noise term and $\triangle$ is the first difference operator. In order to test the existence of long-run equilibrium relationship between $\operatorname{lnCO}_{2}, \operatorname{lnCP}$ index and lnLP_index, the study employs the Fisher's (F) test. The Null hypothesis of no cointegration between $\operatorname{lnCO}_{2}$, lnCP_index and lnLP_index is: $H_{0}: \partial_{1}=\partial_{2}=\partial_{3}=0$ contrary to the Alternative hypothesis $H_{1}: \partial_{1} \neq \partial_{2} \neq \partial_{3} \neq 0$. The computed $F$-statistic is compared with the first critical value known as the lower bound and the second critical value known as an upper bound [26]. The outcome of the comparison is based on three scenarios; if the computed F-statistic goes further than the upper bound then, the null hypothesis of no co-integration between $\operatorname{lnCO}_{2}, \operatorname{lnCP}$ index and lnLP_index is rejected, if the computed F-statistic goes below the lower bound then, the null hypothesis of no co-integration between $\operatorname{lnCO}_{2}$, lnCP_index and lnLP_index cannot be rejected. 


\section{Results and Discussion}

This section presents and discusses on the descriptive statistical analysis and empirical findings vis-à-vis unit root test, Fit regression model, ARDL method of co-integration test, ARDL model selection, long-run elasticities, Granger-causality findings, variance decomposition, diagnostic and stability test results.

\subsection{Descriptive Analysis}

Descriptive statistical analysis is very essential because it describes the basic characteristics of the raw time series data. Table 1 presents the descriptive statistical analysis and the unit root test results of the study variables. While $\operatorname{lnCO}_{2}$ and $\operatorname{lnCP}$ index are positively skewed, lnLP_index is negatively skewed. Nevertheless, $\operatorname{lnCO}_{2}$, lnCP index and lnLP index show a leptokurtic distribution. Based on $5 \%$ significance level, the null hypothesis of normal distribution by the Jarque-Bera statistic cannot be rejected thus, $\mathrm{lnCO}_{2}, \mathrm{lnCP}$ in

Table 1. Descriptive Statistical Analysis

\begin{tabular}{lccc}
\hline & InCO$_{2}$ & InCP_INDEX & InLP_INDEX \\
\hline Mean & 8.236 & 3.8797 & 4.1852 \\
Median & 8.1122 & 3.6028 & 4.3094 \\
Maximum & 9.2203 & 4.9698 & 4.9127 \\
Minimum & 7.2079 & 3.2229 & 3.3069 \\
Std. Dev. & 0.6189 & 0.5547 & 0.4477 \\
Skewness & 0.0746 & 0.5725 & -0.3985 \\
Kurtosis & 1.8514 & 1.8517 & 2.1447 \\
Jarque-Bera & 3.0184 & 5.9162 & 3.0752 \\
Probability & 0.2211 & 0.0519 & 0.2149 \\
Correlation & & & \\
lnCO & & & \\
lnCP_INDEX & 0.9204 & 1 & \\
lnLP_INDEX & 0.9452 & 0.8228 & 1 \\
\hline
\end{tabular}

dex and lnLP_index are normally distributed. Evidence from the correlation statistics shows that lnCP_index and lnLP_index have a positive monotonic relationship with $\operatorname{lnCO}_{2}$.

\subsection{Unit Root Test}

Unit root test is employed to ascertain whether a time series variable is stationary or not [27]. As a pre-requisite for most of the co-integration techniques, the economic variables must be non-stationary at level and stationary at first difference. Augmented Dickey-Fuller (ADF) and Kwiatkowski-Phillips-Schmidt-Shin test statistic are employed in the study as shown in Table 2. Results from the ADF test statistic shows that the null hypothesis of unit root cannot be rejected at the 5\% significance level. At level, KPSS test statistic shows that the null hypothesis of stationarity is rejected at the $5 \%$ significance level. On the other hand, ADF test statistic shows that the null hypothesis of unit root at their first difference is rejected at the $5 \%$ significance level. While KPSS test statistic cannot reject the null hypothesis of stationarity at the $5 \%$ significance level. Mutatis mutandis, $\mathrm{lnCO}_{2}$, lnCP_index and lnLP_index are integrated at I(1).

\subsection{Regression Analysis}

The study employs the fit regression model to determine how carbon dioxide emissions changes as crop production index or livestock production index changes with time. Using equation (2), the resultant regression equation is $\operatorname{lnCO}_{2}=2.958+0.4927$ lnCP_index +0.8044 lnLP_index +0.1316 , where $\beta_{0}=2.96$, $\rho=0.00, \beta_{1}=0.49, \rho=0.00$ and $\beta_{2}=0.80, \rho=0.00$ as shown in Table 2. Evidence from Table 2 shows that the regression $(\rho=0.00)$ and the interaction effect between $\operatorname{lnCO}_{2}, \operatorname{lnCP}$ index and lnLP_index are significant at $1 \%$. The policy implications from the fit regression model shows that; when crop production index increases by $1 \%$, carbon dioxide emissions increases by $0.49 \%$, when livestock production index increases by $1 \%$, carbon dioxide emissions increases by $0.80 \%$ and when both crop and livestock production

Table 2. Unit Root Test

\begin{tabular}{|c|c|c|c|c|c|c|}
\hline & ADF Level & t-Stat & P-Val & KPSS Level & t-Stat & P-Val \\
\hline & Intercept & & & Intercept & & \\
\hline $\operatorname{lnCO}_{2}$ & & -0.1842 & 0.9333 & & 0.8221 & 0.4630 \\
\hline lnCP_INDEX & & 0.9543 & 0.9955 & & 0.8601 & 0.4630 \\
\hline LP_INDEX & & -1.4216 & 0.5649 & & 0.9900 & 0.4630 \\
\hline & Intercept and Trend & & & Intercept and Trend & & \\
\hline $\operatorname{lnCO}_{2}$ & & -2.5361 & 0.3103 & & 0.2465 & 0.1460 \\
\hline lnCP_INDEX & & -1.2013 & 0.8997 & & 0.2566 & 0.1460 \\
\hline lnLP_INDEX & & -1.8146 & 0.6836 & & 0.2110 & 0.1460 \\
\hline & $\begin{array}{l}\text { ADF 1st Diff. } \\
\text { Intercept }\end{array}$ & & & $\begin{array}{l}\text { KPSS 1st Diff. } \\
\text { Intercept }\end{array}$ & & \\
\hline $\operatorname{lnCO}_{2}$ & & -3.2269 & 0.0244 & & 0.3236 & 0.4630 \\
\hline lnCP_INDEX & & -9.4560 & 0.0000 & & 0.1961 & 0.4630 \\
\hline lnLP_INDEX & & -7.2558 & 0.0000 & & 0.2856 & 0.4630 \\
\hline & Intercept and Trend & & & Intercept and Trend & & \\
\hline $\operatorname{lnCO}_{2}$ & & -3.1933 & 0.0979 & & 0.1081 & 0.1460 \\
\hline lnCP_INDEX & & -9.7522 & 0.0000 & & 0.0954 & 0.1460 \\
\hline lnLP_INDEX & & -7.4296 & 0.0000 & & 0.1179 & 0.1460 \\
\hline
\end{tabular}


Table 3. Linear Regression Analysis

\begin{tabular}{|c|c|c|c|c|c|}
\hline \multicolumn{6}{|c|}{ Analysis of Variance } \\
\hline Source & DF & Adj SS & Adj MS & F-Value & P-Value \\
\hline Regression & 2 & 19.4159 & 9.7080 & 560.5600 & 0.0000 \\
\hline lnCP_INDEX & 1 & 1.2787 & 1.2787 & 73.84 & 0.0000 \\
\hline lnLP_INDEX & 1 & 2.2200 & 2.2200 & 128.19 & 0.0000 \\
\hline Error & 51 & 0.8832 & 0.0173 & & \\
\hline Lack-of-Fit & 50 & 0.8802 & 0.0176 & 5.74 & 0.3220 \\
\hline Pure Error & 1 & 0.0031 & 0.0031 & & \\
\hline Total & 53 & 20.2992 & & & \\
\hline \multicolumn{6}{|c|}{ Model Summary } \\
\hline$S$ & R-sq & R-sq(adj) & R-sq(pred) & & \\
\hline 0.1316 & $95.65 \%$ & $95.48 \%$ & $95.12 \%$ & & \\
\hline \multicolumn{6}{|c|}{ Coded Coefficients } \\
\hline Term & Coef & SE Coef & T-Value & P-Value & VIF \\
\hline Constant & 2.9580 & 0.0171 & 17.26 & 0.0000 & \\
\hline lnCP_INDEX & 0.4927 & 0.0573 & 8.59 & 0.0000 & 3.1 \\
\hline lnLP_INDEX & 0.8044 & 0.0711 & 11.32 & 0.0000 & 3.1 \\
\hline
\end{tabular}

index are zero, carbon dioxide emissions increases by $2.96 \%$.

In order to validate and verify the robustness of the fit regression model, the study estimates the lack-of-fit, standard deviation of the error term in the model, R-squared, R-squared of predictor (pred) variable and the variance inflation factor (VIF). Evidence from Table 3 shows that the null hypothesis of lack-of-fit $(\rho=0.32)$ is rejected at $5 \%$ significance level, the standard deviation of the error term $(S=0.13$ ) is lower than 1, the R-squared (R-sq=95.65\%) and the R-squared of predictor (R-sq(pred) $=95.12 \%$ ) are more than 95\% showing how the dependent variable is explained in the model and predicts future data. Since multi-collinearity effect increases the variances of the regression coefficient and makes the prediction erroneous, the study estimates the VIF in the fit regression model. Evidence from Table 3 shows that the VIF of lnCP_ index and lnLP_index is 3.10 , Rule of thumb: VIF $<10$ implies no existence of multicollinearity.

\subsection{Co-integration Test and Model Selection}

Cointegration test is employed to ascertain the long-run equilibrium relationship between $\operatorname{lnCO}_{2}, \operatorname{lnCP}$ index and lnLP_index. Table 4 presents the ARDL bounds test results. Evidence from Table 4 shows that the F-statistic goes beyond the critical value of the upper bound at $1 \%$ significance level, showing a co-integration between $\operatorname{lnCO}_{2}, \mathrm{lnCP}$ index and $\mathrm{lnLP}$ _index.

Fig. 2 depicts the ARDL model selection using the Schwarz Information Criterion. The study employs the Schwarz information criterion (SC) to select the optimal model [ARDL (1, 1, 0)] to estimate the long-run and the short-run equilibrium relationship between the variables. Using the optimal model [ARDL $(1,1,0)]$, the normalized co-integration equation for the ARDL regression analysis is expressed as:

$$
\begin{aligned}
\text { cointeq }= & \ln \mathrm{CO}_{2}-\left(0.5240 \times \ln C P_{-} \text {index }+0.8101 \times\right. \\
& \text { lnLP_inde } x+2.8633)
\end{aligned}
$$

Table 4. ARDL Bounds Test

\begin{tabular}{ccc}
\hline Test Statistic & Value & $\mathbf{k}$ \\
\hline F-statistic & 7.28 & 2 \\
& Critical Value Bounds \\
Significance & I0 Bound & I1 Bound \\
$10 \%$ & 2.63 & 3.35 \\
$5 \%$ & 3.1 & 3.87 \\
$2.50 \%$ & 3.55 & 4.38 \\
$1 \%$ & 4.13 & 5 \\
\hline
\end{tabular}

Schwarz Criteria

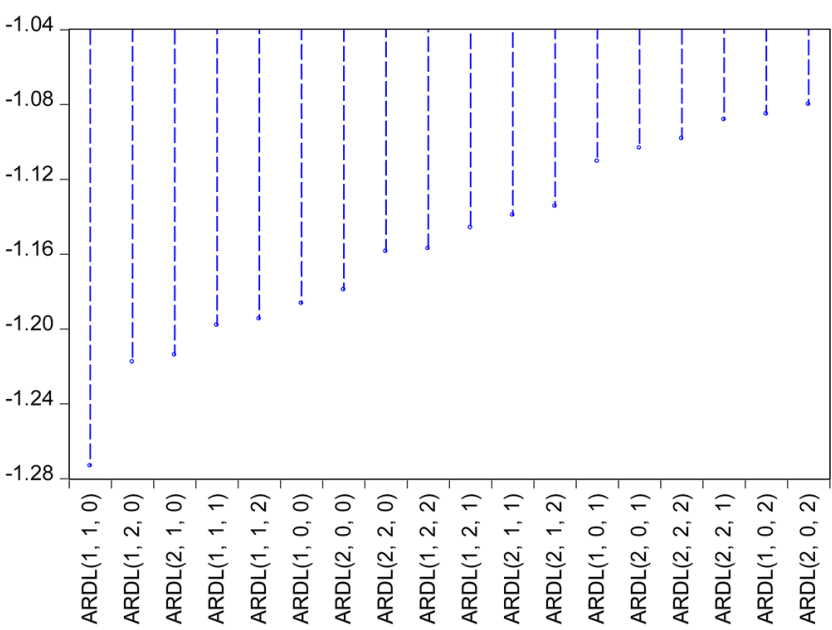

Fig. 2. ARDL model selection criterion.

Based on Eq. (4), the results of the long-run and the short-run equilibrium relationship between $\operatorname{lnCO}_{2}, \operatorname{lnCP}$ index and $\operatorname{lnLP}$ index are presented in Table 5 . The speed of adjustment $\left(E C T_{t-1}=-0.58\right)$ which correct deviations in the long-run and the short-run relation 
Table 5. Long-run and Short-run Relationship Estimation

\begin{tabular}{lcccc}
\hline \multicolumn{1}{c}{ Variable } & Coefficient & Std. Error & t-Statistic & Prob. \\
\hline lnCP_INDEX & -0.1557 & 0.1435 & -1.0853 & 0.2832 \\
lnLP_INDEX & 0.4465 & 0.3309 & 1.3496 & 0.1835 \\
ECT (-1) & -0.5803 & 0.1102 & -5.2658 & 0.0000 \\
& & Long-Run & \\
Variable & Coefficient & Std. Error & t-Statistic & Prob. \\
lnCP_INDEX & 0.5240 & 0.0857 & 6.1129 & 0.0000 \\
lnhLP_INDEX & 0.8101 & 0.1077 & 7.5192 & 0.0000 \\
C & 2.8633 & 0.2638 & 10.8557 & 0.0000 \\
\hline
\end{tabular}

ship between $\mathrm{lnCO}_{2}$, lnCP_index and $\mathrm{lnLP}$ _index near equilibrium is negative and significant at the $1 \%$ level. Table 4 shows an evidence of a long-run equilibrium relationship running from lnCP_index and lnLP_index to $\operatorname{lnCO}_{2}$. However, there is no significant short-run relationship between $\operatorname{lnCO}_{2}, \operatorname{lnCP}$ index and lnLP_index.

\subsection{Diagnostic and Stability Checks}

The ARDL model was validated and verified using a series of diagnostic and stability checks to scrutinize the independence of the residuals from the fitted model. For a robust ARDL model, the residuals must exhibit the required independence during the diagnostic and stability checks, if not, the model is unacceptable statistically and requires further model modification before additional diagnostic and stability checks. In this way, the ARDL model becomes unbiased and robust to make the correct statistical inferences. Table 6 presents the diagnostic test for the ARDL model.

Diagnostic tests employed to validate the ARDL model include; Heteroskedasticity Test, Breusch-Godfrey Serial Correlation LM Test, Jarque-Bera Test and Ramsey RESET Test as presented in Table 6. ARDL residual heteroskedasticity was tested with Breusch-Pagan-Godfrey Test statistic. Evidence from Table 6 shows that the ARDL residual Heteroskedasticity Test cannot reject the null hypothesis of no conditional heteroskedasticity at the 5\% significance level. Meaning that, no conditional heteroskedasticity exists in the residuals of the ARDL model. The ARDL residual serial correlation was tested with Breusch-Godfrey Serial Correlation LM Test statistic. Evidence from Table 5 shows that the null hypothesis of no serial correlation at lag order $\mathrm{h}$ cannot be rejected at the $5 \%$ significance level. Meaning that, no serial correlation exists at lag order h. ARDL functional misspecification was estimated with Ramsey RESET Test statistic. Evidence from Table 6 shows that the null hypothesis of functional form cannot be rejected at the $5 \%$ significance level. Meaning that, there the ARDL model is in its functional form. ARDL residual normal distribution was tested with Jarque-Bera test statistic. Evidence from Table 6 shows that the null hypothesis of multivariate normal distribution cannot be rejected at the $5 \%$ significance level. Meaning that, the ARDL residuals are normally distributed.

In order to estimate the structural stability of the equation in the ARDL model, the study employed the CUSUM and CUSUM of Squares residual tests. Fig. 3 shows the CUSUM and CUSUM of Squares residual tests of the ARDL Model. Evidence from Fig. 3
Table 6. ARDL Model Diagnostic Tests

\begin{tabular}{|c|c|c|c|}
\hline \multicolumn{4}{|c|}{ Diagnostic Tests } \\
\hline \multicolumn{4}{|c|}{ Heteroskedasticity Test: Breusch-Pagan-Godfrey } \\
\hline F-statistic & 1.5591 & Prob. $F(8,42)$ & 0.1665 \\
\hline \multicolumn{4}{|c|}{ Breusch-Godfrey Serial Correlation LM Test } \\
\hline F-statistic & 0.49029 & Prob. F(2,40) & 0.6161 \\
\hline \multicolumn{4}{|c|}{ Jarque-Bera Test } \\
\hline Jarque-Bera & 0.507432 & Probability & 0.7759 \\
\hline \multicolumn{4}{|c|}{ Ramsey RESET Test } \\
\hline & Value & $\mathrm{df}$ & p-value \\
\hline F-statistic & 2.0928 & $(1,41)$ & 0.1556 \\
\hline
\end{tabular}
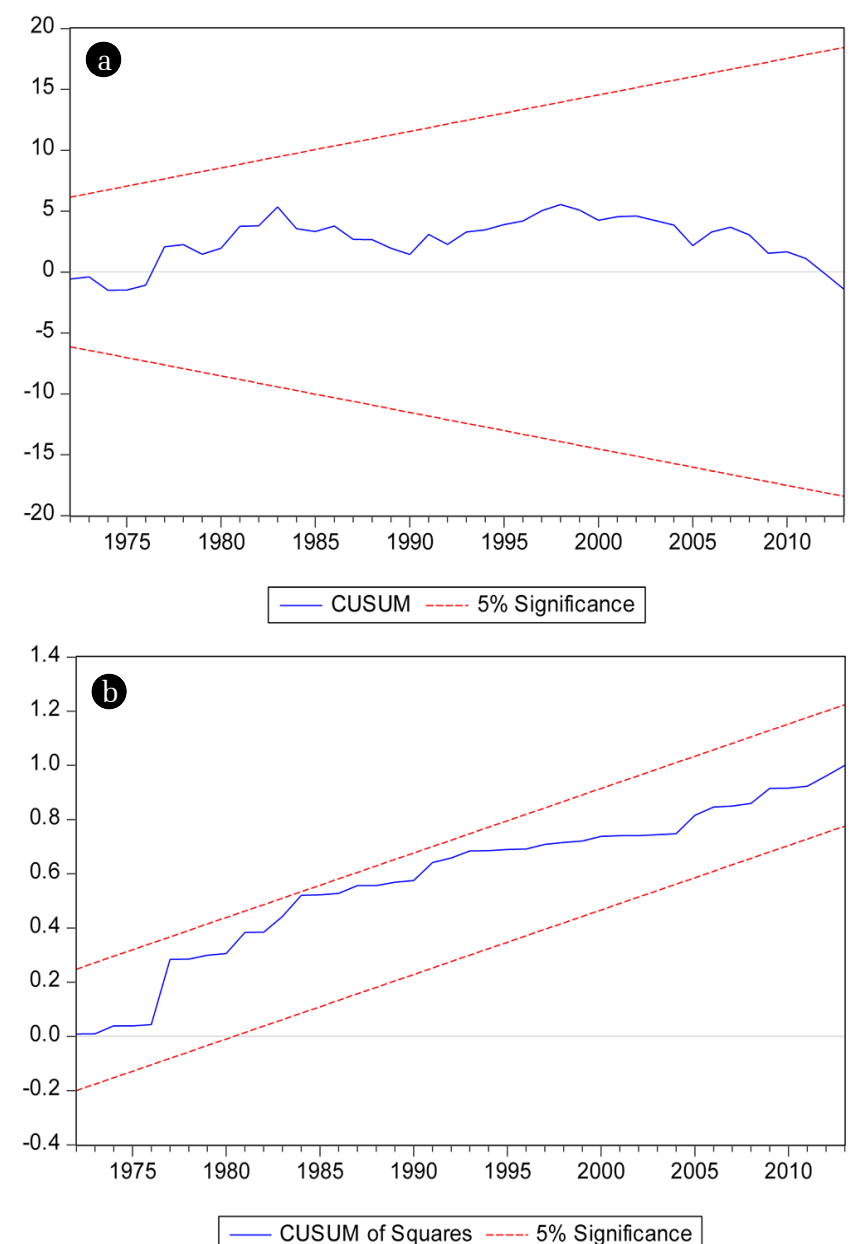

Fig. 3. Stability test based on (a) CUSUM and (b) CUSUM of Squares.

shows that all the plots in CUSUM and CUSUM of Squares residual tests lie within the $5 \%$ significance level. Meaning that, the estimated parameters of the equation in the ARDL model are constant and stable to verify and validate the evidence of ARDL cointegration bound test, the long-run and short-run causality, Granger-causality and Cholesky technique of variance decomposition in the study. In other words, the ARDL model is robust and meets stability conditions to make unbiased statistical inferences. 
Table 7. Granger-causality Tests

\begin{tabular}{|c|c|c|}
\hline Null Hypothesis: & F-Statistic & Prob. \\
\hline lnCP_INDEX does not Granger Cause $\operatorname{lnCO}_{2}$ & 5.8990 & $0.0188^{*}$ \\
\hline $\operatorname{lnCO}_{2}$ does not Granger Cause lnCP_INDEX & 5.2350 & 0.0264 * \\
\hline lnLP INDEX does not Granger Cause $\operatorname{lnCO}_{2}$ & 5.0349 & $0.0293^{*}$ \\
\hline $\operatorname{lnCO}_{2}$ does not Granger Cause lnLP_INDEX & 1.2153 & 0.2756 \\
\hline lnLP_INDEX does not Granger Cause lnCP_INDEX & 2.8534 & 0.0974 \\
\hline lnCP_INDEX does not Granger Cause lnLP_INDEX & 0.2669 & 0.6077 \\
\hline
\end{tabular}

${ }^{*}$ rejection of the null hypothesis at $5 \%$ significance level

\subsection{Granger-causality}

The study employs the Granger-causality test based on VECM to estimate the direction of causality between $\operatorname{lnCO}_{2}, \operatorname{lnCP}$ index and lnLP_index. Table 7 presents the results of the Granger-causality tests. The null hypothesis that lnCP_INDEX does not Granger Cause $\operatorname{lnCO} \mathrm{CO}_{2}, \operatorname{lnCO}_{2}$ does not Granger Cause lnCP_INDEX and lnLP_INDEX does not Granger Cause $\operatorname{lnCO}_{2}$ is rejected at the 5 $\%$ significance level. Meaning that, there is a bidirectional causality between crop production index and carbon dioxide emissions (lnCP INDEX $\leftrightarrow \operatorname{lnCO}{ }_{2}$ ). As some echelon of carbon dioxide is required by crops for photosynthesis, certain crops like cereals releases methane, carbon dioxide and nitrous oxide into the atmosphere during pre-harvest and post-harvest crop production.

Table 6 shows evidence of a unidirectional causality from livestock production index to carbon dioxide (lnLP_INDEX $\rightarrow \operatorname{lnCO_{2}}$ ) however, the reverse is invalid. The results from Table 7 confirm the long-run elasticity estimates that livestock production index increases carbon dioxide emissions.

\subsection{Variance Decomposition}

This section estimates the response of $\operatorname{lnCO}_{2}, \operatorname{lnCP}$ index and lnLP_index to each other in one standard deviation innovations using the vector autoregression (VAR). The variance decomposition provides evidence on the relative importance of each random innovation in affecting $\mathrm{lnCO}_{2}, \mathrm{lnCP}$ index and $\mathrm{lnLP}$ index in the VAR. Table 8 presents the variance decomposition of $\mathrm{lnCO}_{2}$, lnCP_index and lnLP_index within a 10-period horizon. From Table 8, almost $37 \%$ of future fluctuations in $\operatorname{lnCO}_{2}$ are due to shocks in lnCP_index while $18 \%$ of future fluctuations in $\operatorname{lnCO}_{2}$ are due to shocks in lnLP_index. According to Think.Eat.Save [10], the nitrogen fertilizers use in crop production, diesel use for ploughing the agricultural land, harvesting and drying of crops like cereals all results in carbon dioxide emissions. Exclusively, rice production takes a big share of climate change and its impacts. Rice paddies are the major emitters of methane. Nevertheless, the crop production index will reduce carbon dioxide emissions in Ghana more than the livestock production index in the long-run, if sustainable agriculture measures are taken into consideration.

Furthermore, $9 \%$ of future fluctuations in lnCP_index are due to shocks in $\mathrm{lnCO}_{2}$ while $7 \%$ of future fluctuations in lnCP_index are due to shocks in lnLP_index. Meaning that carbon dioxide emissions will affect the crop production index either positively or negatively in the future more than the livestock production
Table 8. Variance Decomposition of $\operatorname{lnCO} \mathrm{C}_{2}, \ln C P$ INDEX and InLP_INDEX

\section{Variance Decomposition}

Variance Decomposition of $\ln \mathrm{CO}_{2}$ :

\begin{tabular}{ccccc} 
Period & S.E. & $\operatorname{lnCO}_{2}$ & lnCP_INDEX & InLP_INDEX \\
1 & 0.1086 & 100 & 0 & 0 \\
2 & 0.1129 & 96.0414 & 0.0469 & 3.9117 \\
3 & 0.1145 & 95.4097 & 0.7179 & 3.8724 \\
4 & 0.1191 & 88.4388 & 6.8778 & 4.6833 \\
5 & 0.1242 & 81.6574 & 12.0366 & 6.3060 \\
6 & 0.1315 & 72.7554 & 18.1389 & 9.1057 \\
7 & 0.1397 & 64.6302 & 23.6844 & 11.6854 \\
8 & 0.1492 & 56.7426 & 28.9596 & 14.2979 \\
9 & 0.1593 & 50.0793 & 33.5116 & 16.4092 \\
10 & 0.1698 & 44.3892 & 37.4562 & 18.1546 \\
\multicolumn{5}{c}{ Variance Decomposition of InCP INDEX: }
\end{tabular}

$\begin{array}{ccccc}\text { Period } & \text { S.E. } & \operatorname{lnCO}_{2} & \text { lnCP_INDEX } & \text { lnLP_INDEX } \\ 1 & 0.1011 & 4.7474 & 95.2526 & 0 \\ 2 & 0.1267 & 3.0457 & 96.9409 & 0.0133 \\ 3 & 0.1557 & 3.4913 & 95.2203 & 1.2884 \\ 4 & 0.1829 & 5.8177 & 92.1813 & 2.0010 \\ 5 & 0.2125 & 6.5447 & 89.9153 & 3.5400 \\ 6 & 0.2396 & 7.3850 & 88.0824 & 4.5326 \\ 7 & 0.2658 & 7.9775 & 86.5515 & 5.4710 \\ 8 & 0.2910 & 8.5910 & 85.2512 & 6.1578 \\ 9 & 0.3154 & 9.0455 & 84.2289 & 6.7255 \\ 10 & 0.3388 & 9.4427 & 83.3928 & 7.1645\end{array}$

Variance Decomposition of InLP_INDEX:

\begin{tabular}{ccccc} 
Period & S.E. & $\operatorname{lnCO}_{2}$ & $\operatorname{lnCP}$ INDEX & lnLP_INDEX \\
1 & 0.0342 & 0.4361 & 1.0069 & 98.5570 \\
2 & 0.0462 & 0.8129 & 4.6826 & 94.5045 \\
3 & 0.0554 & 3.9304 & 4.6161 & 91.4534 \\
4 & 0.0613 & 6.1807 & 5.6603 & 88.1589 \\
5 & 0.0664 & 8.3291 & 6.3223 & 85.3486 \\
6 & 0.0703 & 9.8256 & 6.7356 & 83.4388 \\
7 & 0.0738 & 11.2196 & 6.8650 & 81.9154 \\
8 & 0.0768 & 12.3051 & 6.8198 & 80.8751 \\
9 & 0.0795 & 13.1600 & 6.6528 & 80.1872 \\
10 & 0.0819 & 13.7898 & 6.4004 & 79.8098 \\
\hline
\end{tabular}


index in Ghana. In other words, certain echelons of carbon dioxide are required to increase yield and productivity, however, the extreme echelons of carbon dioxide emissions are dangerous to cropping patterns, yield and adaptability to pest and disease control.

Finally, almost $14 \%$ of future fluctuations in lnLP_index are due to shocks in $\operatorname{lnCO}_{2}$ while $6 \%$ of future fluctuations in $\operatorname{lnLP}$ index are due to shocks in lnCP_index. Meaning that carbon dioxide emissions will affect livestock production index either positively or negatively in the future more than the crop production index in Ghana. Increasing levels of carbon dioxide emissions in Ghana will in the long-run affect livestock production index due to changes in weather patterns that will affect their survival, which will gradually lead to their extinction.

\subsection{Carbon Footprint}

Carbon footprint estimates the cumulated carbon dioxide emissions produced by an individual, organization or a country. According to Think.Eat.Save [10], if food waste were a country, it will be the third largest emitter of greenhouse gas, after the USA and China. Quantitatively, Think.Eat.Save [10] revealed that the major contributors to the carbon footprint of food wastage are cereals (34\%), followed by meat (21\%) and vegetables (21\%). Products of animal origin account for about $33 \%$ of the total carbon footprint. Among all food commodities, meat and milk have the biggest food waste footprint, in terms of land occupation. Meat and milk contribute $78 \%$, more than three-fourth of the total food waste surface.

As explained, the time series data employed from the World Bank factored cereals, meat and vegetables in the data for crop and livestock production index. Therefore, the results of long-run elasticity estimates can be used to explain Ghana's carbon footprint. Evidence from the long-run elasticities will provide a direction for Ghana's future crop and livestock production towards achieving sustainable agriculture while reducing its carbon footprint and mitigating climate change and its impacts. Fig. 4 depicts the analysis of Ghana's carbon footprint using the Granger-causality, ARDL long-run elasticities and variance decomposition. The ARDL long-run elasticities in Table 4 confirm the results from the fit regression model.

Evidence from Table 4 shows that a $1 \%$ increase in crop production index (lnCP_index) will increase (elastic) carbon dioxide emissions by $0.52 \%$, while a $1 \%$ increase in livestock production index (lnLP_index) will increase (elastic) carbon dioxide emissions by $0.81 \%$ in the long-run as depicted in Fig. 4 . According to Asumadu-Sarkodie and Owusu [16], "Ghana's GDP as in 2010 from crop production accounted for $66.2 \%$, forestry accounted for $12.2 \%$, fisheries accounted for $7.3 \%$, cocoa production accounted for $8.2 \%$ and livestock production accounted for $6.1 \%$ respectively". Even though, crop production accounted for $66.2 \%$ of Ghana's GDP, yet $1 \%$ increase will increase carbon dioxide emissions by $0.52 \%$ compared to livestock production that accounted for only $8.2 \%$ of Ghana's GDP yet increases carbon dioxide emissions by $0.81 \%$. Asumadu-Sarkodie and Owusu [16] revealed that, Ghana's "livestock production has been increasing from 1999 to 2010 . Cattle production rose from $1,288,000$ heads to $1,454,000$

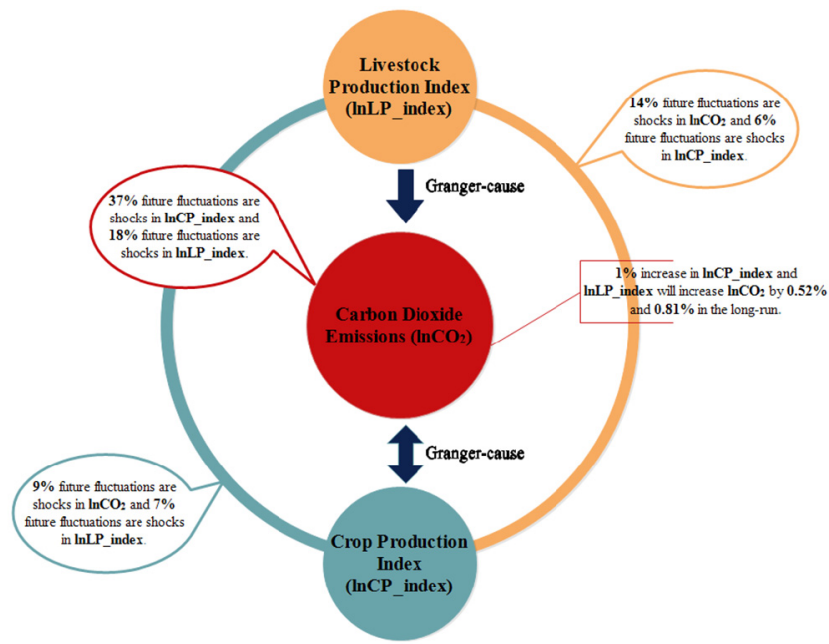

Fig. 4. Analysis of Ghana's carbon footprint.

heads, sheep production rose from 2,658,000 heads to $3,779,000$ heads, goat production rose from $2,931,000$ heads to $4,855,000$ heads, pig production rose from 332,000 heads to 536,000 heads, and poultry production rose from $18,810,000$ birds to $43,320,000$ birds". Increasing carbon dioxide emissions in Ghana from livestock production can be associated with enteric fermentation of ruminants, feed production, livestock production, manure management, livestock transportation, and livestock processing. Another reason is due to poor agricultural practices since the majority of the farmers in Ghana lives in rural areas without access to productive resources, knowledge and financial services toward sustainable agricultural practices.

\section{Policy Recommendations}

The Sustainable Development Goal 2 [7] seeks to "end hunger, achieve food security, improve nutrition and promote sustainable agriculture". Following the evidence from the study, the following recommendations are made:

It is highly appreciable the role of agriculture as a backbone in feeding every nation towards achieving healthy living and increasing economic growth. Nevertheless, Government's effort towards ensuring sustainable agricultural know-how of farmers within the rural areas in Ghana will be a first step towards climate change mitigation.

Government of Ghana's effort towards integrating climate change mitigation options and plans into agricultural sectoral policies is essential towards achieving sustainable agriculture.

Efforts towards reducing pre-production, production, transportation, processing and post-harvest losses are essential to reducing food wastage which affects Ghana's carbon footprint.

Finally, Government of Ghana's effort towards investing and promoting scientific research in technological advancement in crop yield, crop adaptation to carbon dioxide emissions, reduced methane emissions from ruminants, etc. will be essential to achieving a sustainable agriculture. 


\section{Conclusions}

Joining the global campaign to reduce our carbon footprint is one option to help combat climate change and its impacts. As a result, the study estimated the relationship between carbon dioxide, crop and food production index in Ghana: Estimating the long-run elasticities and variance decomposition. In order to meet the goal; the study investigated the relationship between carbon dioxide, crop and livestock production index, the study estimated the long-run equilibrium relationship between carbon dioxide, crop and livestock production index and estimated the variance decomposition between carbon dioxide, crop and livestock production index using Cholesky's technique.

The study employed a time series data spanning from 1960-2013, obtained from the World Bank database. The methodology employed in the study included fit regression model, ARDL model, Granger-causality tests and variance decomposition. Diagnostic and stability tests in the study revealed that the fit regression and the ARDL models are robust and meets stability conditions to make unbiased statistical inferences.

There was a significant evidence of a long-run equilibrium relationship between carbon dioxide emissions, crop production index and livestock production index at $1 \%$ significance level. Using a Wald test of linear restrictions on the joint coefficients based of the ARDL model, there was evidence of the short-run equilibrium relation from crop and livestock production index to carbon dioxide emissions. The results of long-run elasticity estimates were used to explain Ghana's carbon footprint. Evidence from the study shows that a $1 \%$ increase in crop production index will increase (elastic) carbon dioxide emissions by $0.52 \%$, while a $1 \%$ increase in livestock production index will increase (elastic) carbon dioxide emissions by $0.81 \%$ in the long-run.

There was evidence of a bidirectional causality between crop production index and Carbon dioxide emissions (lnCP_INDEX $\leftrightarrow$ $\mathrm{lnCO}_{2}$ ) and a unidirectional causality exists from livestock production index to Carbon dioxide emissions ( $\mathrm{lnLP}$ INDEX $\rightarrow \operatorname{lnCO}_{2}$ ) however, the reverse was invalid.

Evidence from the variance decomposition analysis shows that; almost $37 \%$ of future fluctuations in Carbon dioxide emissions are due to shocks in the crop production index while $18 \%$ of future fluctuations in Carbon dioxide emissions are due to shocks in the livestock production index. Furthermore, 9\% of future fluctuations in crop production index are due to shocks in Carbon dioxide emissions while $7 \%$ of future fluctuations in crop production index are due to shocks in the livestock production index. Moreover, almost $14 \%$ of future fluctuations in the livestock production index are due to shocks in Carbon dioxide emissions while $6 \%$ of future fluctuations in the livestock production index are due to shocks in the crop production index.

As a recommendation, Government's effort towards integrating climate change mitigation options and plans into agricultural sectoral policies in Ghana is essential towards achieving sustainable agriculture. Future research should focus on how each of the animal species or livestock production contributes to Carbon dioxide emissions.

\section{References}

1. Asumadu-Sarkodie S, Owusu PA. Feasibility of biomass heating system in Middle East Technical University, Northern Cyprus Campus. Cogent Eng. 2016;3:1134304.

2. Asumadu-Sarkodie S, Owusu P. A review of Ghana's energy sector national energy statistics and policy framework. Cogent Eng. 2016;3:1155274.

3. Owusu P, Asumadu-Sarkodie S. A review of renewable energy sources, sustainability issues and climate change mitigation. Cogent Eng. 2016;3:1167990.

4. Owusu PA, Asumadu-Sarkodie S, Ameyo P. A review of Ghana's water resource management and the future prospect. Cogent Eng. 2016;3:1164275.

5. Earth System Research Laboratory. The NOAA Annual Greenhouse Gas Index (AGGI) [Internet]. c2015[cited 24 October 2015]. Available from: http://www.esrl.noaa.gov/gmd/ aggi/aggi.html.

6. Asumadu-Sarkodie S, Sevinç Ç, Jayaweera HMPC. A hybrid solar photovoltaic-wind turbine-rankine cycle for electricity generation in Turkish Republic Of Northern Cyprus. Cogent Eng. 2016;3:1180740.

7. United Nations. Sustainable development goals [Internet]. c2015 [cited 24 October 2015]. Available from: https:// sustainabledevelopment.un.org/?menu=1300.

8. Asumadu-Sarkodie S, Owusu PA. The potential and economic viability of wind farms in Ghana. Energ. Source. Part A. 2016;38: 695-701.

9. Asumadu-Sarkodie S, Owusu PA. The potential and economic viability of solar photovoltaic power in Ghana. Energ. Source. Part A. 2016;38:709-716.

10. Think.Eat.Save. Reduce your foodprint [Internet]. c2014 [cited 15 November 2014]. Available from: http://thinkeatsave.org/.

11. Hauggaard-Nielsen H, Lachouani P, Knudsen MT, Ambus P, Boelt B, Gislum R. Productivity and carbon footprint of perennial grass-forage legume intercropping strategies with high or low nitrogen fertilizer input. Sci. Total Environ. 2016;541: 1339-1347.

12. Persson UM, Henders S, Cederberg C. A method for calculating a land-use change carbon footprint (LUC-CFP) for agricultural commodities - applications to Brazilian beef and soy, Indonesian palm oil. Glob. Change Biol. 2014;20:3482-3491.

13. Picasso VD, Modernel PD, Becona G, Salvo L, Gutierrez L, Astigarraga L. Sustainability of meat production beyond carbon footprint: A synthesis of case studies from grazing systems in Uruguay. Meat Sci. 2014;98:346-354.

14. Laurent A, Olsen SI, Hauschild MZ. Limitations of carbon footprint as indicator of environmental sustainability. Environ. Sci. Technol. 2012;46:4100-4108.

15. Asumadu-Sarkodie S, Owusu PA. Carbon dioxide emissions, GDP, energy use and population growth: a multivariate and causality analysis for Ghana, 1971-2013. Environ. Sci. Pollut. Res. Int. 2016;23:13508-13520.

16. Asumadu-Sarkodie S, Owusu PA. The relationship between carbon dioxide and agriculture in Ghana: A comparison of VECM and ARDL model. Environ. Sci. Pollut. Res. Int. 2016;23:10968-10982. 
17. Wang S, Li Q, Fang C, et al. The relationship between economic growth, energy consumption, and $\mathrm{CO}_{2}$ emissions: Empirical evidence from China. Sci. Total Environ. 2016;542(Pt A): 360-371.

18. Apergis N, Ozturk I. Testing environmental Kuznets curve hypothesis in Asian countries. Ecol. Indic. 2015;52:16-22.

19. Asumadu-Sarkodie S, Owusu P. The casual nexus between child mortality rate, fertility rate, GDP, household final consumption expenditure, and food production index. Cogent Econ. Fin. 2016;4:1191985.

20. Mohiuddin O, Asumadu-Sarkodie S, Obaidullah M. The relationship between carbon dioxide emissions, energy consumption, and GDP: A recent evidence from Pakistan. Cogent Eng. 2016;3:1210491.

21. Asumadu-Sarkodie S, Owusu PA. Energy use, carbon dioxide emissions, GDP, industrialization, financial development, and population, a causal nexus in Sri Lanka: With a subsequent prediction of energy use using neural network. Energ. Source.
Part B. 2016;11:889-899.

22. Asumadu-Sarkodie S, Owusu PA. Multivariate co-integration analysis of the Kaya factors in Ghana. Environ. Sci. Pollut. Res. Int. 2016;23:9934-9943.

23. Bildirici ME. Relationship between biomass energy and economic growth in transition countries: Panel ARDL approach. GCB Bioenergy 2014;6:717-726.

24. World Bank. Data [Internet]. c2015 [cited 12 November 2015]. Available from: http://data.worldbank.org/.

25. Pesaran MH, Shin Y. An autoregressive distributed-lag modelling approach to cointegration analysis. Econ. Soc. Monogr. 1998;31:371-413.

26. Pesaran MH, Shin Y, Smith RJ. Bounds testing approaches to the analysis of level relationships. J. Appl. Econom. 2001;16:289-326.

27. Dickey DA, Fuller WA. Distribution of the estimators for autoregressive time series with a unit root. J. Am. Stat. Assoc.1979; 74:427-431. 